\title{
Overcoming male factor infertility with intracytoplasmic sperm injection
}

\author{
Edson Borges JR. ${ }^{1 *}$, Bianca Ferrarini Zanetti², Daniela Paes de Almeida Ferreira Braga ${ }^{3}$, Amanda Souza Setti \\ Rita de Cássia Sávio Figueira ${ }^{5}$, Aguinaldo César Nardi ${ }^{6}$, Assumpto laconelli JR. ${ }^{7}$

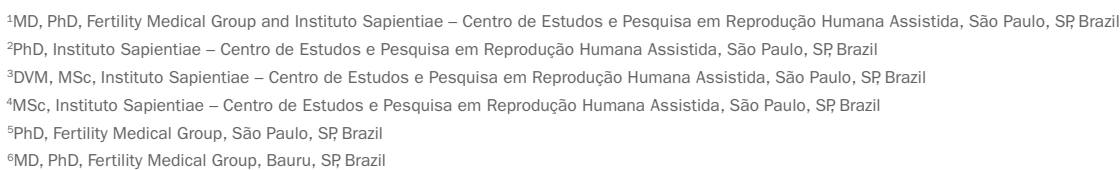

Study conducted at Fertility Medical Group and Instituto Sapientiae - Centro de Estudos e Pesquisa em Reprodução Humana Assistida, São Paulo, SP, Brazil

Article received: $7 / 3 / 2017$ Accepted for publication: 7/21/2017

*Correspondence: Address: Av. Brigadeiro Luis Antônio, 4.545 São Paulo, SP - Brazil Postal code: 01401-002 edson@fertility.com.br

http://dx.doi.org/10.1590/1806-9282.63.08.697

\section{SUMmARY}

Objective: To evaluate the effect of male factor infertility on intracytoplasmic sperm injection (ICSI) outcomes compared with a control group presenting isolated tubal factor.

Method: This retrospective study included 743 couples undergoing ICSI as a result of isolated male factor and a control group consisting of 179 couples undergoing ICSI as a result of isolated tubal factor, performed in a private university-affiliated in vitro fertilization center, between January/2010 and December/2016. Patients were divided into two groups according to maternal age: women $\leq 35$ years old and $>35$ years old. The effects of infertility causes on laboratorial and clinical ICSI outcomes were evaluated using Student's t-test and $\chi^{2}$ test.

Results: No differences in controlled ovarian stimulation outcomes were observed between male factor cycles and tubal factor cycles in the two age groups. Implantation (male factor $35.5 \%$ vs. tubal factor $32.0 \%, \mathrm{p}=0.340$ ), pregnancy (male factor $46.9 \%$ vs. tubal factor $40.9 \%, \mathrm{p}=0.184$ ) and miscarriage (male factor $10.3 \%$ vs. tubal factor $10.6 \%, \mathrm{p}=0.572$ ) rates were similar between the infertility groups, irrespective of female age. Considering maternal age, the cancelation rate was higher in older women ( $>35$ years old) undergoing ICSI as a result of male factor infertility $(17.4 \%$ vs. $8.9 \%, \mathrm{p}=0.013)$.

Conclusion: Our results showed that there is no difference in the outcomes of pregnancy between couples with male or tubal factor infertility, which indicates that ICSI surpasses the worse specific outcomes associated with male factor.

Keywords: spermatozoa/abnormalities, intracytoplasmic sperm injections, evaluation of results of therapeutic interventions, pregnancy.

\section{INTRODUCTION}

The male factor, which is the single most common cause of infertility, is solely responsible for $30 \%$ of infertility cases and contributory in an additional $30 \%$ of cases. ${ }^{1-3}$ Although successful outcomes have been obtained in cases of male factor infertility, conventional in vitro fertilization (IVF) has proved ineffective for patients with seminal parameters that do not meet the minimum cut-off values determined by the World Health Organization., ${ }^{4,5}$

The advent of intracytoplasmic sperm injection (ICSI) improved the odds of pregnancy in patients with seminal abnormalities, such as reduced sperm count, motility and percentage of morphologically normal cells. ${ }^{6}$ Through ICSI, it is now possible to obtain satisfactory pregnancy rates even when few spermatozoa are found in the ejaculate or surgically recovered from testicles/epididymis, which was almost impossible through classical IVF.?

Even though the general consensus is that ICSI should be the first treatment option only in the presence of extremely poor sperm samples, ${ }^{8}$ it is routinely used for causes of infertility other than male factor. It has been reported that ICSI usage in the United States of America has in- 
creased, from 2008 to 2012, whereas the incidence of male factor infertility has remained unchanged. ${ }^{9}$ Therefore, the increase in ICSI usage is likely to be also occurring in couples with infertility causes other than male factor, despite the evidence that ICSI does not benefit non-male factor patients. ${ }^{10}$

The Center for Disease Control reported that ICSI was used in up to $78 \%$ of non-male factor ART cycles in the USA. ${ }^{11}$ In fact, ICSI overcomes some IVF difficulties, such as zona pellucida abnormalities that prevents sperm fusion to the oolema; ${ }^{12,13}$ zona pellucida hardening and consequent inhibition of natural sperm penetration in cryopreserved oocytes; ${ }^{14,15}$ and DNA contamination from additional sperm that would be adhering to the zona pellucida in preimplantation genetic diagnosis (PGD) cycles. ${ }^{16}$

Overall, the use of ICSI has not been shown to cause any more negative effects than those seen with IVF., ${ }^{917}$ ICSI actually enhances normal fertilization rate, since the requirement for cumulus cells removal allowed a better visualization of oocytes structure and maturity, and led to a better oocyte selection. ${ }^{18}$ Moreover, spermatozoa selection made ICSI the preferred line of treatment regardless of the infertility cause. ${ }^{19,20}$

Few studies have investigated whether or not ICSI surpasses the worse specific outcomes associated with male factor. Therefore, the goal of this study was to evaluate the effect of isolated male factor on laboratorial and clinical ICSI outcomes compared with a control group presenting isolated tubal factor, according to maternal age.

\section{Method}

\section{Study design}

This retrospective study included 922 ICSI cycles, of which 743 were attributed to isolated male infertility and 179 to isolated tubal factor. Only first cycle with fresh own embryo transfer were included. Cycles were performed in a private university-affiliated IVF center, between January 2010 and December 2016.

In the first analysis, the effects of infertility causes on (i) the number of follicles; (ii) the number of retrieved oocytes; (iii) oocyte yield; (iv) number of mature oocytes; (v) mature oocyte rate; (vi) fertilization rate; (vii) normal fertilization rate; (viii) embryo quality at cleavage stage; (ix) blastocyst formation rate; (x) cycle's cancelation rate; (xi) implantation rate; (xii) pregnancy rate and (xiii) miscarriage rate were compared between the groups.

In the second analysis, women were divided into two groups according to maternal age: $\leq 35$-old group $(\mathrm{n}=643)$ and $>35 \mathrm{y}$-old group $(\mathrm{n}=279)$.

Written informed consent, in which patients agreed to share the outcomes of their cycles for research pur- poses, were obtained, and the local institutional review board approved the study.

\section{Controlled ovarian stimulation}

Controlled ovarian stimulation (COS) was achieved using a daily dose of recombinant FSH (r-FSH, Gonal-F®, Merck KGaA, Darmstadt, Germany), beginning on the third day of the cycle. Pituitary blockage was performed using a GnRH antagonist (GnRHa, Cetrotide®; Merck KGaA, Darmstadt, Germany), beginning when at least one follicle measuring $\geq 14 \mathrm{~mm}$ in diameter was visualized on ultrasound exam.

When adequate follicular growth and serum E2 levels were observed, recombinant hCG (r-hCG, Ovidrel ${ }^{\circledR}$, Merck KGaA, Darmstadt, Germany) was administered to trigger final follicular maturation. The oocytes were collected 35 hours later through transvaginal ultrasound-guided ovum pick-up.

\section{Preparation of oocytes}

Retrieved oocytes were maintained in culture medium (Global ${ }^{\circledR}$ for fertilization, LifeGlobal, Connecticut, USA) supplemented with $10 \%$ protein supplement (LGPS, LifeGlobal, Connecticut, USA) and covered with paraffin oil (Paraffin oil P.G., LifeGlobal, Connecticut, USA) for 2 to 3 hours before the removal of cumulus cells. The surrounding cumulus cells were removed after exposure to a HEPES-buffered medium containing hyaluronidase (80 IU/mL, LifeGlobal, Connecticut, USA). The remaining cumulus cells were mechanically removed by gently pipetting with a hand-drawn Pasteur pipette (Humagen Fertility Diagnostics, Charlottesville, USA).

The oocyte morphology was assessed immediately before sperm injection (four hours after retrieval) using an inverted Nikon Diaphot microscope (Eclipse TE 300; Nikon ${ }^{\circledR}$, Tokyo, Japan) with a Hoffmann modulation contrast system under 400X magnification. Oocytes that released the first polar body were considered mature and used for ICSI.

\section{Intracytoplasmic sperm injection}

Intracytoplasmic sperm injection was performed in a microinjection dish prepared with 4- $\mu \mathrm{L}$ droplets of buffered medium (Global ${ }^{\circledR}$ w/HEPES, LifeGlobal, Connecticut, USA) and covered with paraffin oil on the heated stage of an inverted microscope $\left(37.0 \pm 0.5^{\circ} \mathrm{C}\right)$. Approximately 16 hours after ICSI, fertilization was confirmed by the presence of two pronuclei and the extrusion of the second polar body. Embryos were maintained in a $50-\mu \mathrm{L}$ drop of culture medium (Global ${ }^{\oplus}$, LifeGlobal, Connecticut, USA), supplemented with $10 \%$ protein supplement and covered with paraffin oil in a humidified atmosphere under $6 \% \mathrm{CO}_{2}$ at $37^{\circ} \mathrm{C}$ for five days. 


\section{Embryo morphology evaluation}

Embryo morphology was assessed 16-18 hours post-ICSI and on the mornings of days 2, 3 and 5 using an inverted Nikon Diaphot microscope (Eclipse TE 300; Nikon, Tokyo, Japan) with a Hoffmann modulation contrast system under 400X magnification.

To evaluate cleavage-stage morphology, the following parameters were recorded: number of blastomeres, percentage of fragmentation, variation in blastomere symmetry, presence of multinucleation, and defects in the zona pellucida and cytoplasm. High-quality cleavage stage embryos were defined as those with all of the following characteristics: 4 cells on day 2, or 8-10 cells on day 3, $<10 \%$ fragmentation, symmetric blastomeres, absence of multinucleation, colorless cytoplasm with moderate granulation and no inclusions, absence of perivitelline space granularity, and absence of zona pellucida dysmorphisms. Embryos lacking any of these characteristics were considered to be of low quality.

To evaluate the blastocyst-stage morphology, the size and compactness of the ICM and the cohesiveness and number of TE cells were recorded. The ICM of full, expanded, hatching and hatched blastocysts were classified as either high-quality (tightly packed with many cells) or low-quality (loosely grouped with several or few cells). Similarly, the TE were classified as either high-quality (many cells forming a cohesive epithelium) or low-quality (few cells forming a loose epithelium or very few cells).

Embryo transfer was performed on the third or fifth day of development.

\section{Clinical follow-up}

A pregnancy test was performed 12 days after embryo transfer. All women with a positive test had a transvaginal ultrasound scan two weeks after the positive test. A clinical pregnancy was diagnosed when the fetal heartbeat was detected.

Implantation rate was defined as the number of gestational sacs divided by the number of embryos transferred per patient. Pregnancy was defined as the presence of a gestational sac with heartbeat visualized by ultrasound 4-6 weeks after embryo transfer. Pregnancy rates were calculated per transfer. Miscarriage was defined as pregnancy loss before 20 weeks.

\section{Statistical analysis}

The effects of infertility causes on aforementioned laboratorial and clinical outcomes were evaluated by Student t-test for continuous variables and Chi-square test for categorical variables. The results are expressed as means \pm standard deviation (SD) and $\mathrm{p}$-value for continuous variables, while percentages and $\mathrm{p}$-value are used for categorical variables. The $\alpha$ adopted was $5 \%$. Statistical analysis was performed using IBM SPSS 20 Software.

\section{Results}

From a total of 3,273 first ICSI cycles with fresh own embryo transfer performed between January 2010 and December 2016, 922 were suitable for analysis. Of those, 743 cycles were attributed to pure male infertility factors and 179 to pure tubal infertility factor were included in the analysis.

In the first analysis, mean female age was higher in tubal factor patients, while mean male age was higher in male factor patients. Patients with tubal factor had worse ovarian response to COS, represented by lower number of aspirated follicles, retrieved and mature oocytes. However, a higher fertilization rate was noted compare to male factor patients. Despite the higher number of transferred embryos in male factor patients, the implantation rate was similar between groups. The cancelation rate was higher in patients with male factor, but pregnancy and miscarriage rates were similar between the groups (Table 1).

In the second analysis, in order to exclude a possible influence of maternal age on the results, women were divided into two groups according to age: $\leq 35 y$-old group (531 male factor cases and 112 tubal factor cases); and > $35 \mathrm{y}$-old group (212 cases male factor cases and 67 tubal factor cases).

The effects of the infertility cause on the outcomes of ICSI in the $\leq 35 \mathrm{y}$-old group are described in Table 2 . No differences in COS outcomes were observed between the groups. The fertilization rate remained higher in tubal factor patients, while the number of transferred embryos was higher in male factor patients. Clinical outcomes were similar between the groups.

The effects of the infertility cause on the outcomes of ICSI in the $>35 \mathrm{y}$-old are described in Table 3 . The only significant difference observed was in cycle cancelation rate, which was higher in male factor patients. All the other analyzed variables were similar between the groups.

\section{Discussion}

Before 1992, conventional IVF could not address many issues related to male factor infertility and relied on normal or nearly normal sperm counts. The development of ICSI has revolutionized the field with regard to male infertility, but outcomes from such cases have not been well elucidated. Our study evaluated the effects of male factor, compared to a control group with isolated tubal factor, on laboratorial and clinical ICSI outcomes. Tubal factor was chosen as a reference group to act specifically as the control for the iat- 
TABLE 1 Effects of the infertility causes on laboratorial and clinical ICSI outcomes.

\begin{tabular}{|c|c|c|c|}
\hline Variables & Male factor $(n=743)$ & Tubal factor $(n=179)$ & $\mathrm{p}$-value \\
\hline Female age ( $y$-old) & $33.16 \pm 3.91$ & $33.85 \pm 3.79$ & 0.033 \\
\hline Male age ( $y$-old) & $37.75 \pm 7.37$ & $36.59 \pm 5.65$ & 0.022 \\
\hline \multicolumn{4}{|l|}{ COS outcomes } \\
\hline Aspirated follicles (n) & $19.98 \pm 10.74$ & $17.93 \pm 10.44$ & 0.022 \\
\hline Retrieved oocytes (n) & $14.79 \pm 8.91$ & $13.39 \pm 8.81$ & 0.060 \\
\hline Oocyte yield (\%) & $73.55 \pm 18.53$ & $74.80 \pm 19.00$ & 0.422 \\
\hline Mature oocytes (n) & $10.97 \pm 6.91$ & $9.58 \pm 6.40$ & 0.014 \\
\hline Mature oocyte rate (\%) & $74.26 \pm 18.13$ & $72.77 \pm 18.74$ & 0.329 \\
\hline \multicolumn{4}{|l|}{ Laboratorial outcomes } \\
\hline Fertilization rate (\%) & $82.28 \pm 18.09$ & $85.64 \pm 14.81$ & 0.010 \\
\hline Normal fertilization rate (\%) & $75.72 \pm 20.50$ & $78.42 \pm 18.36$ & 0.109 \\
\hline High-quality embryo at D3 (\%) & $48.26 \pm 28.56$ & $44.51 \pm 29.83$ & 0.158 \\
\hline Blastocyst formation rate (\%) & $42.10 \pm 26.64$ & $43.00 \pm 29.04$ & 0.772 \\
\hline Transferred embryos (n) & $1.68 \pm 0.67$ & $1.50 \pm 0.61$ & 0.004 \\
\hline \multicolumn{4}{|l|}{ Clinical outcomes } \\
\hline Implantation rate (\%) & $35.55 \pm 42.21$ & $32.00 \pm 42.20$ & 0.340 \\
\hline Cancelation rate & $121 / 743(16.3 \%)$ & $18 / 179(10 \%)$ & 0.036 \\
\hline Pregnancy rate & $292 / 622(46.9 \%)$ & $66 / 161(40.9 \%)$ & 0.184 \\
\hline Miscarriage rate & $31 / 302(10.3 \%)$ & $7 / 66(10.6 \%)$ & 0.572 \\
\hline
\end{tabular}

COS: controlled ovarian stimulation.

TABLE 2 Effects of the infertility causes on laboratorial and clinical ICSI outcomes in the $\leq 35 y$-old group. $\leq 35$ y-old women

\begin{tabular}{|c|c|c|c|}
\hline Variables & Male factor $(n=531)$ & Tubal factor $(n=112)$ & p-value \\
\hline Female age (y-old) & $31.36 \pm 2.99$ & $31.71 \pm 3.05$ & 0.273 \\
\hline Male age (y-old) & $36.27 \pm 6.98$ & $35.02 \pm 5.27$ & 0.036 \\
\hline \multicolumn{4}{|l|}{ COS outcomes } \\
\hline Aspirated follicles (n) & $21.40 \pm 10.92$ & $19.93 \pm 10.87$ & 0.198 \\
\hline Retrieved oocytes (n) & $15.96 \pm 9.21$ & $15.04 \pm 9.40$ & 0.340 \\
\hline Oocyte yield (\%) & $74.40 \pm 18.13$ & $76.08 \pm 18.74$ & 0.376 \\
\hline Mature oocytes (n) & $11.87 \pm 7.18$ & $10.65 \pm 6.66$ & 0.099 \\
\hline Mature oocyte rate (\%) & $74.75 \pm 17.19$ & $73.08 \pm 17.12$ & 0.353 \\
\hline \multicolumn{4}{|l|}{ Laboratorial outcomes } \\
\hline Fertilization rate (\%) & $82.66 \pm 17.32$ & $86.43 \pm 14.08$ & 0.015 \\
\hline Normal fertilization rate (\%) & $76.41 \pm 19.71$ & $78.78 \pm 18.41$ & 0.245 \\
\hline High-quality embryo at D3 (\%) & $49.71 \pm 27.72$ & $45.29 \pm 28.10$ & 0.172 \\
\hline Blastocyst formation rate (\%) & $43.55 \pm 26.93$ & $45.76 \pm 29.59$ & 0.565 \\
\hline Transferred embryos (n) & $1.70 \pm 0.63$ & $1.52 \pm 0.61$ & 0.012 \\
\hline \multicolumn{4}{|l|}{ Clinical outcomes } \\
\hline Implantation rate (\%) & $37.33 \pm 42.06$ & $34.52 \pm 43.36$ & 0.553 \\
\hline Cancelation rate & $84 / 531(15.8 \%)$ & $14 / 112(12.5 \%)$ & 0.232 \\
\hline Pregnancy rate & $222 / 447(49.6 \%)$ & $42 / 98(43 \%)$ & 0.456 \\
\hline Miscarriage rate & $22 / 222(9.9 \%)$ & $3 / 42(7.1 \%)$ & 0.369 \\
\hline
\end{tabular}

ICSI: intracytoplasmic sperm injection; COS: controlled ovarian stimulation. 
TABLE 3 Effects of the infertility causes on laboratorial and clinical ICSI outcomes in the $>35 y$-old group.

\begin{tabular}{|c|c|c|c|}
\hline \multicolumn{4}{|c|}{$>35$ y-old women } \\
\hline Variable & Male factor $(n=212)$ & Tubal factor $(n=67)$ & p-value \\
\hline Female age $(y / o)$ & $37.66 \pm 1.68$ & $37.43 \pm 1.54$ & 0.336 \\
\hline Male age $(y / o)$ & $41.55 \pm 6.99$ & $39.16 \pm 5.33$ & 0.004 \\
\hline \multicolumn{4}{|l|}{ COS outcomes } \\
\hline Aspirated follicles (n) & $16.44 \pm 9.43$ & $14.63 \pm 8.82$ & 0.165 \\
\hline Retrieved oocytes (n) & $11.87 \pm 7.36$ & $10.67 \pm 6.99$ & 0.240 \\
\hline Oocyte yield (\%) & $71.45 \pm 19.39$ & $72.68 \pm 19.37$ & 0.651 \\
\hline Mature oocytes (n) & $8.71 \pm 5.56$ & $7.81 \pm 5.53$ & 0.247 \\
\hline Mature oocyte rate (\%) & $73.03 \pm 20.28$ & $72.25 \pm 21.27$ & 0.789 \\
\hline \multicolumn{4}{|l|}{ Laboratorial outcomes } \\
\hline Fertilization rate (\%) & $81.33 \pm 19.92$ & $84.31 \pm 15.99$ & 0.270 \\
\hline Normal fertilization rate (\%) & $73.98 \pm 22.33$ & $77.83 \pm 18.40$ & 0.206 \\
\hline High-quality embryo at D3 (\%) & $44.66 \pm 30.33$ & $43.31 \pm 32.53$ & 0.772 \\
\hline Blastocyst formation rate (\%) & $37.70 \pm 25.36$ & $37.96 \pm 27.73$ & 0.960 \\
\hline Transferred embryos (n) & $1.62 \pm 0.75$ & $1.48 \pm 0.62$ & 0.161 \\
\hline \multicolumn{4}{|l|}{ Clinical outcomes } \\
\hline Implantation rate (\%) & $31.03 \pm 42.38$ & $28.12 \pm 40.37$ & 0.635 \\
\hline Cancelation rate & $37 / 212(17.4 \%)$ & $4 / 67(8.9 \%)$ & 0.013 \\
\hline Pregnancy rate & $70 / 175(40 \%)$ & $24 / 63(38 \%)$ & 0.456 \\
\hline Miscarriage rate & $8 / 70(11.4 \%)$ & $4 / 24(16.6 \%)$ & 0.338 \\
\hline
\end{tabular}

ICSI: intracytoplasmic sperm injection; COS: controlled ovarian stimulation.

rogenesis of ICSI technique. Our results showed that there is no difference in the pregnancy and miscarriage rates between couples with male or tubal factor, irrespective of maternal age.

Adequate female age is a pivotal factor determining successful outcomes, even when severe male factor is the main fertility cause. ${ }^{21}$ In our study, we subdivided our sample into two age groups, younger women $(\leq 35$ years old) and older women ( $>35$ years old), to reduce the bias of maternal age on outcomes. In younger women, we observed a higher fertilization rate in the tubal factor group and a higher number of transferred embryos in the male factor group, but these differences did not impact the implantation rate and subsequent pregnancy rate, which were similar between infertility groups.

A higher cancelation rate was observed only in couples with male factor and older women. In this group, paternal age was also higher and may have impacted this outcome, since sperm morphology parameters decline significantly with age and may affect the availability of good spermatozoa to fertilize. ${ }^{22,23}$

The high normal fertilization and implantation rates after ICSI evidences that male factor do not interfere with the success rate of this technology, as was also reported by many other groups. ${ }^{24,25}$
The embryo quality and blastocyst formation were not influenced by male factor infertility. In fact, other studies comparing embryos obtained through classical IVF or ICSI with sperm from severe male infertility showed that they had potential similar developmental viabilities, ${ }^{26,27}$ and pregnancy, miscarriage and live birth rates are similar after adjustment for maternal factors. ${ }^{9,21}$

A similar study comparing male and tubal factors showed that male factor infertility was related to lower pregnancy rate and a trend toward lower live birth rate. ${ }^{28}$ Concerning perinatal outcomes, ICSI for male factor infertility was also not associated with changes in length of gestation, baby birth weight, sex ratio, rate of pregnancy loss and congenital malformations in other reports. ${ }^{28-30}$

The main limitations of this study are (i) its retrospective nature and (ii) the fact that male factor was defined as the cause of infertility, but it was not subdivided into different male infertility diagnoses as they exist for female factor infertility, so the severity of the male factor infertility could not be determined.

\section{Conclusion}

Our results showed that there is no difference in the clinical outcomes between couples with male or tubal factor infertility, which indicates that ICSI surpasses the worse 
specific outcomes associated with male factor. An appropriate $\operatorname{COS}$ and endometrial preparation may have major impact on ICSI outcomes, rather than the infertility cause.

\section{Resumo}

Superando o fator masculino de infertilidade com injeção intracitoplasmática de espermatozoides

Objetivo: Avaliar o efeito do fator masculino de infertilidade em resultados de injeção intracitoplasmática de espermatozoides (ICSI) em comparação com um grupo controle que apresenta o fator tubário isolado.

Método: Este estudo retrospectivo incluiu 743 casais submetidos a ICSI por fator masculino e 179 casais por fator tubário, realizada em um centro privado de fertilização in vitro associado à universidade, entre janeiro de 2010 e dezembro de 2016. Os pacientes foram divididos em dois grupos de acordo com a idade materna: mulheres $\leq 35 \mathrm{e}$ $>35$ anos de idade. Os efeitos das causas de infertilidade nos resultados laboratoriais e clínicos da ICSI foram avaliados pelos testes T de Student e Qui-quadrado.

Resultados: Não foram observadas diferenças nos parâmetros de estimulação ovariana entre os ciclos com fatores masculinos e com fatores tubários. A taxa de implantação (fator masculino $35,5 \% v$ s. fator tubário 32,0\%, $\mathrm{p}=0,340$ ), de gravidez (fator masculino $46,9 \% v s$. fator tubário $40,9 \%$, $\mathrm{p}=0,184$ ) e de aborto (fator masculino $10,3 \%$ vs. fator tubário $10,6 \%, p=0.572$ ) foram semelhantes entre os grupos de infertilidade, independentemente da idade feminina. Considerando a idade materna, a taxa de cancelamento foi maior em mulheres > 35 anos cuja causa de infertilidade era o fator masculino $(17,4 \% v s .8,9 \%, \mathrm{p}=0,013)$.

Conclusão: Não há diferenças nos resultados de gravidez entre casais com infertilidade dos fatores masculino ou tubário isolados, o que indica que ICSI supera os piores resultados associados ao fator masculino.

Palavras-chave: espermatozoides/anormalidades, injeções intracitoplasmáticas de espermatozoides, avaliação de resultado de intervenções terapêuticas, gravidez.

\section{References}

1. Smit M, Romijn JC, Wildhagen MF, Weber RF, Dohle GR. Sperm chromatin structure is associated with the quality of spermatogenesis in infertile patients. Fertil Steril. 2010; 94(5):1748-52.

2. Trost LW, Nehra A. Guideline-based management of male infertility: Why do we need it? Indian J Urol. 2011; 27(1):49-57.

3. Henkel R, Maaß G, Bödeker RH, Scheibelhut C, Stalf T, Mehnert C, et al. Sperm function and assisted reproduction technology. Reprod Med Biol. $2005 ; 4(1): 7-30$
4. Cooper TG, Noonan E, von Eckardstein S, Auger J, Baker HW, Behre HM, et al. World Health Organization reference values for human semen. Hum Reprod Update. 2010; 16(3):231-45.

5. Yovich JL, Stanger JD. The limitations of in vitro fertilization from males with severe oligospermia and abnormal sperm morphology. J In Vitro Fert Embryo Transf. 1984; 1(3):172-9.

6. Palermo G, Joris H, Devroey P, Van Steirteghem AC. Pregnancies after intracytoplasmic injection of single spermatozoon into an oocyte. Lancet. 1992; 340(8810): 17-8.

7. Vernaeve V, Bonduelle M, Tournaye H, Camus M, Van Steirteghem A, Devroey P. Pregnancy outcome and neonatal data of children born after ICSI using testicular sperm in obstructive and non-obstructive azoospermia. Hum Reprod. 2003; 18(10):2093-7.

8. Palermo GD, Neri QV, Schlegel PN, Rosenwaks Z. Intracytoplasmic sperm injection (ICSI) in extreme cases of male infertility. PLoS ONE. 2014; 9(12):e113671.

9. Boulet SL, Mehta A, Kissin DM, Warner L, Kawwass JF, Jamieson DJ. Trends in use of and reproductive outcomes associated with intracytoplasmic sperm injection. JAMA. 2015; 313(3):255-63.

10. Bhattacharya S, Hamilton MP, Shaaban M, KhalafY, Seddler M, Ghobara $\mathrm{T}$, et al. Conventional in-vitro fertilisation versus intracytoplasmic sperm injection for the treatment of non-male-factor infertility: a randomised controlled trial. Lancet. 2001; 357(9274):2075-9.

11. CDC. 2013Assisted Reproductive Technology Fertility Clinic Success Rates Report. Available from: https:/www.cdc.gov/art/reports/2013/fertilityclinic.html

12. Palermo GD, Cohen J, Rosenwaks Z. Intracytoplasmic sperm injection: a powerful tool to overcome fertilization failure. Fertil Steril. 1996; 65(5):899-908.

13. Bedford JM, Kim HH. Sperm/egg binding patterns and oocyte cytology in retrospective analysis of fertilization failure in vitro. Hum Reprod. 1993; $8(3): 453-63$.

14. Van Blerkom J, Henry G. Oocyte dysmorphism and aneuploidy in meiotically mature human oocytes after ovarian stimulation. Hum Reprod. 1992; $7(3): 379-90$.

15. Van Blerkom J, Davis PW. Cytogenetic, cellular, and developmental consequences of cryopreservation of immature and mature mouse and human oocytes. Microsc Res Tech. 1994; 27(2):165-93.

16. Harton GL, De Rycke M, Fiorentino F, Moutou C, SenGupta S, TraegerSynodinos J, et al.; European Society for Human Reproduction and Embryology (ESHRE) PGD Consortium. ESHRE PGD consortium best practice guidelines for amplification-based PGD. Hum Reprod. 2011; 26(1):33-40.

17. Tournaye H. Male factor infertility and ART. Asian J Androl. 2012; 14(1):103-8.

18. Rienzi L, Balaban B, Ebner T, Mandelbaum J. The oocyte. Hum Reprod. 2012; 27 (Suppl 1):i2-21.

19. Kim JY, Kim JH, Jee BC, Lee JR, Suh CS, Kim SH. Can intracytoplasmic sperm injection prevent total fertilization failure and enhance embryo quality in patients with non-male factor infertility? Eur J Obstet Gynecol Reprod Biol. 2014; 178:188-91.

20. Practice Committees of the American Society for Reproductive Medicine and Society for Assisted Reproductive Technology. Intracytoplasmic sperm injection (ICSI) for non-male factor infertility: a committee opinion. Fertil Steril. 2012; 98(6):1395-9.

21. Oehninger S, Veeck L, Lanzendorf S, Maloney M, Toner J, Muasher S. Intracytoplasmic sperm injection: achievement of high pregnancy rates in couples with severe male factor infertility is dependent primarily upon female and not male factors. Fertil Steril. 1995; 64(5):977-81.

22. Hellstrom WJ, Overstreet JW, Sikka SC, Denne J, Ahuja S, Hoover AM, et al. Semen and sperm reference ranges for men 45 years of age and older. J Androl. 2006; 27(3):421-8.

23. Eskenazi B, Wyrobek AJ, Sloter E, Kidd SA, Moore L, Young S, et al. The association of age and semen quality in healthy men. Hum Reprod. 2003; $18(2): 447-54$

24. Van Steirteghem AC, Nagy Z, Joris H, Liu J, Staessen C, Smitz J, et al. High fertilization and implantation rates after intracytoplasmic sperm injection. Hum Reprod. 1993; 8(7):1061-6.

25. Aboulghar MA, Mansour RT, Serour GI, Amin YM. The role of intracytoplasmic sperm injection (ICSI) in the treatment of patients with borderline semen. Hum Reprod. 1995; 10(11):2829-30. 
26. Ludwig M, Katalinic A; German ICSI Follow-Up Study Group. Pregnancy course and health of children born after ICSI depending on parameters of male factor infertility. Hum Reprod. 2003; 18(2):351-7.

27. Zheng JF, Chen XB, Zhao LW, Gao MZ, Peng J, Qu XQ, et al. ICSI treatment of severe male infertility can achieve prospective embryo quality compared with IVF of fertile donor sperm on sibling oocytes. Asian J Androl. 2015; 17(5):845-9.

28. Nangia AK, Luke B, Smith JF, Mak W, Stern JE; SART Writing Group. National study of factors influencing assisted reproductive technology outcomes with male factor infertility. Fertil Steril. 2011; 96(3):609-14.
29. Oldereid NB, Hanevik HI, Bakkevig I, Romundstad LB, Magnus $\varnothing$, Hazekamp $\mathrm{J}$, et al. Pregnancy outcome according to male diagnosis after ICSI with nonejaculated sperm compared with ejaculated sperm controls. Reprod Biomed Online. 2014; 29(4):417-23.

30. Vaegter KK, Lakic TG, Olovsson M, Berglund L, Brodin T, Holte J. Which factors are most predictive for live birth after in vitro fertilization and intracytoplasmic sperm injection (IVF/ICSI) treatments? Analysis of 100 prospectively recorded variables in 8,400 IVF/ICSI single-embryo transfers. Fertil Steril. 2017; 107(3):641-648.e2. 